\title{
The career destination of doctors who graduated from a medical college in Goa, India between 2000-2005: A retrospective cohort study
}

\author{
Umesh S. Kamat ${ }^{1}$, A.M.A. Ferreira ${ }^{2}$ \\ ${ }^{1}$ Assistant Lecturer, ${ }^{2}$ Associate Professor, Department of Preventive and Social Medicine, Goa Medical College, Goa, India.
}

\begin{abstract}
The problem of health manpower shortage in developing countries appears to arise from brain drain or poor inclination of qualified medicos towards medical practice. This study was conducted among the alumni of an allopathic medical college in Goa to find out the proportion of Goan doctors who remain allied to the medical field 5 years after graduating, and to examine the extent of brain drain among these doctors. The doctors who graduated between the years 2000-2005 were contacted through email/telephone/residential address to obtain the relevant information. Of the 383 doctors who graduated during the reference period, $96.6 \%$ could be traced, and out of these, 166 were male and 204 were female. The proportion of non-practicing doctors is $23.5 \%$, and as many as $41 \%$ of the female medical graduates are not currently in medical profession. All the non-practicing female doctors were married, $52.9 \%(46 / 87)$ settled abroad and $31 \%(27 / 87)$ settled out of Goa. More than $41 \%$ of medically affiliated doctors worked out of Goa. Among those working in Goa 50.6\% (84/166) worked for government health services, 31.9\% $(53 / 166)$ were attached to a private hospital/clinic, and $17.5 \%$ (29/166) were academically affiliated. None of the practicing doctors do general practice on their own. Given the steadily increasing number of female medical graduates who constitute the bulk of non-practicing doctors it is imperative to bring in legislation stating minimum years of medical practice for every medical graduate. The brain drain of nearly $50 \%$ is an issue of concern, as also is the reduced number of doctors engaged in general practice.
\end{abstract}

Keywords: Doctors, Shortage, Career planning, Brain drain, India.

\section{Introduction}

Man, money, material and minutes (time) are the four prime resources in healthcare management. Of these, qualified health personnel are the most important as they need to effectively manage the others and deliver the best public health output. ${ }^{1}$ Health manpower shortage has been a persistent problem in India, like in other developing countries. ${ }^{2-7}$ Each year more than 30000 doctors graduate from 335 allopathic medical colleges in the country and the number is expected to double in the years to come. ${ }^{8}$ However, this appears to only pacify the policy makers of their chronic fear of doctor deficiency, as the core issue is inequitable distribution of health manpower in urban favour $^{1,2}$ and medical drain to the developed world. ${ }^{2-7}$ With more than 60000 Indian doctors practicing in US, UK, Canada and Australia (year 2006), India stands as the major contributor of medical brainpower to the developed world. ${ }^{9}$ A sum total of this results in to an apparent shortage of health manpower in India, a condition of scarcity amidst plenty.

Goa is a small state with population of around 1.5 million spread over the area of $3702 \mathrm{sq}$. km. With almost $50 \%$ rural-urban differentiation, the per capita income is almost Rs 50000 compared to the national average of close to Rs. 18,000 . There is only one government allopathic medical

\section{Practice Points}

- Health manpower shortage has been the biggest problem in India in providing effective health care.

- Brain drain accounts for almost $1 / 3^{\text {rd }}$ of the medical manpower.

- More than $41 \%$ of the female medical graduates do not practice medicine.

- Medical graduates prefer clinical specializations to general practice as career.

- Strategies need to be planned and implemented to stop the brain drain and retain the medical personnel to provide effective health care.

college in the state with the current annual admission capacity of 150 . The number of the doctors registered with Goa Medical Council till April 2013 is 3,043, with doctor population ratio of 1:543, compared with 1:2148 for the country. ${ }^{10}$ The figures, however, seem attractive only on paper and the attrition of the recent

Correspondence: Dr. Umesh S. Kamat, Assistant Lecturer, Department of Preventive and Social Medicine, Goa Medical College, Goa, India. E-mail: neetumesh@,rediffmail.com.

South East Asia Journal of Public Health 2013;3(1):65-68. (c) 2013 Kamat \& Ferreira, publisher and licensee Public Health Foundation Bangladesh. This is an Open Access article which permits unrestricted non-commercial use, provided the original work is properly cited. 
medical graduates from the medical practice or the practice in Goa is increasingly acknowledged. This study was carried out to estimate the proportion of medical graduates who remained affiliated to the medical practice after a minimum of 5 years following graduation and of those who did, how many practice in Goa and elsewhere.

\section{Materials and methods}

List of the doctors of Goan origin who passed out from Goa Medical College Hospital during the years 20002005 was obtained from the office of the Registrar, Goa Medical Council. The office maintains the list in the order of registration numbers along with the details of the residential/e-mail addresses and contact numbers. In the first stage the doctors who could be easily traced were identified. These doctors were then presented with the list of their batch-mates to obtain their contact details (phone numbers/e-mail addresses). The doctors identified in the subsequent stages were asked to contribute towards tracking their other batch mates from the list. The identified doctors were e-mailed a short questionnaire which included information on their marital status, current place of residence, current occupation and affiliation. The study proposal was approved by the institutional review board of Goa Medical College, Bambolim. The data was entered into SPSS for windows, version 10.5 and described as proportions. Chi square test was used to test the significance of difference between the proportions at $95 \%$ confidence level.

\section{Results}

Of the 383 doctors who graduated during the reference period, 370 individuals (166 males and 204 females) could be traced (Table 1). A steady increase in the number of females graduating every successive year is noteworthy, as is the significantly higher number of females graduates compared to the males during the years 2000-2005.

Of the 370 doctors, $234(63.2 \%)$ pursued postgraduate education, $38.1 \%(141 / 370)$ masters and above, and $25.3 \%(93 / 370)$ diplomas, while the rest stopped at MBBS. The proportion of non-practicing doctors is $23.5 \%$, and as many as $41 \%$ of the female medical graduates are not currently in medical profession (Table 2 ). All the non-practicing female doctors were married, $32 \%(27 / 84)$ to medical professionals while $68 \%$ (57/84) to non-medicos; $54.8 \%$ (46/84) settled abroad and $32.1 \%(27 / 84)$ settled out of Goa in India. Forty nine $(58.3 \%)$ of the female doctors showed no inclination towards medical practice, $34.5 \%(29 / 84)$ were in-
Table 1: Number of medical graduates: 2000-2005

\begin{tabular}{|l|l|l|c|}
\hline Year & Males & Females & Total \\
\hline 2000 & $40(58.8 \%)$ & $28(41.2 \%)$ & 68 \\
\hline 2001 & $42(57.5 \%)$ & $31(42.5 \%)$ & 73 \\
\hline 2002 & $30(47.6 \%)$ & $33(52.4 \%)$ & 63 \\
\hline 2003 & $20(36.4 \%)$ & $35(63.6 \%)$ & 55 \\
\hline 2004 & $17(29.3 \%)$ & $41(70.7 \%)$ & 58 \\
\hline 2005 & $17(32.1 \%)$ & $36(67.9 \%)$ & 53 \\
\hline Total & $166(44.9 \%)$ & $204(55.1 \%)$ & 370 \\
\hline
\end{tabular}

( $\mathrm{SE}$ of difference in proportions $=2.58$ )

terested in initiating medical practice but not sure when, while $10.7 \%(9 / 84)$ had it next on agenda after their immediate family commitment was taken care of. Thus the doctors who remained affiliated to the medical field after at least 6 years of their graduation were only $76.5 \%$; $98.8 \%$ males and $58.8 \%$ females. Of the medically non-affiliated doctors $73.6 \%(64 / 87)$ were just MBBS, $18.4 \%(16 / 87)$ had a post-graduate diploma and $4.6 \%(4 / 87)$ had a post-graduate degree. The reasons for not practicing medicine, as commonly stated by the respondents included child care (72.6\%), loss of interest in the medical field (17.9\%) and frequent touring with the husband $(9.5 \%)$.

Of the 283 doctors currently in the medical field, 117 $(41.3 \%)$ work out of Goa: $21.9 \%(62 / 283)$ in India and $19.4 \%(55 / 283)$ abroad (Table 3). Among the doctors practicing in Goa $50.6 \%(84 / 166), 52.5 \%(52 / 99)$ males and $47.8 \%(32 / 67)$ females, work in government health services; $31.9 \%(53 / 166), 29.3 \%$ (29/99) males and $35.8 \%(24 / 67)$ females, work in private sectors; and $17.5 \%$ (29/166), $18.2 \%(18 / 99)$ males and $16.4 \%$ $(11 / 67)$ females work in the teaching hospitals. Of the doctors working in the private sector in Goa, none have started their general practice clinics.

\section{Discussion}

On an average 61 doctors of Goan origin passed out every year during the years 2000-2005, in which females have clearly outnumbered males. Of these $23.5 \%$ are not currently in medical practices while $31.6 \%$ work out of Goa, leaving only $44.9 \%$ of the total doctors at the service of the state. These account for only $32.8 \%$ $(67 / 204)$ of the female and $59.6 \%(99 / 166)$ of the male graduates during the time frame. The study identifies 3 major problem areas with respect to the medical practice patterns of the recent medical graduates in Goa: brain drain, non-practicing doctors, particularly females, and poor inclination to general practice.

Table 2: Current affiliation of the doctors (n-370)

\begin{tabular}{|l|c|c|c|c|}
\hline \multicolumn{1}{|c|}{ Affiliation } & Males & Females & Total & $p$-value \\
\hline Private sector & $79(47.6 \%)$ & $69(33.8 \%)$ & $148(40 \%)$ & $<0.01$ \\
\hline Govt health services & $56(33.7 \%)$ & $32(15.7 \%)$ & $88(23.8 \%)$ & $<0.01$ \\
\hline Academic institution & $28(16.9 \%)$ & $19(9.3 \%)$ & $47(12.7 \%)$ & $<0.05$ \\
\hline Non-medical & $3(1.8 \%)$ & $84(41.2 \%)$ & $87(23.5 \%)$ & $<0.001$ \\
\hline
\end{tabular}

South East Asia Journal of Public Health 2013;3(1):65-68 
Table 3: Distribution of the doctors according to their place of work

\begin{tabular}{|l|c|c|c|}
\hline \multicolumn{1}{|c|}{ Place of working } & Males & Females & Total \\
\hline In Goa & $99(60.7 \%)$ & $67(55.8 \%)$ & $166(58.7 \%)$ \\
\hline Other parts of India & $28(17.2 \%)$ & $34(28.3 \%)$ & $62(21.9 \%)$ \\
\hline Out of India & $36(22.1 \%)$ & $19(15.8 \%)$ & $55(19.4 \%)$ \\
\hline Total & 163 & 120 & 283 \\
\hline
\end{tabular}

\section{Brain drain}

Emigration of medical talent in search of green pastures across the borders is, an age old entity, referred to as brain drain. ${ }^{4-7,9}$ A study similar to this among the alumni of AIIMS, New Delhi between the years 1989-2000 showed that almost $54 \%$ of the graduates settled abroad $^{5}$. Almost $10 \%$ of the Indian doctors are practicing in US, UK, Canada and Australia constituting 4.9\% of the physician workforce in the US and $10.9 \%$ in the UK. ${ }^{9} \quad$ Better standards of living and quality of life, higher salaries, access to advanced technology and more stable political conditions in the developed countries are known to attract talent from less developed areas. ${ }^{11-18}$

The disadvantages to the source countries in terms of futile investment in the medical education of the emigrants and lack of their contribution to the local health systems, though obvious, are often overlooked. Variety of social political modifications and policy changes are recommended ${ }^{19-23}$ to encourage 'professional mobility' so that the emigrated medical personnel came back to their native state. This would be beneficial as the medical personnel with higher medical qualifications and exposure to advanced medical technology would strengthen the local health system. However, the gap between the sociopolitical, economic and technological situation between the developed and the source countries is so wide that the proportion of those returning back home is meagre. 9,17

\section{Non practicing doctors}

Four out of 10 female medical graduates of the study cohort currently do not practice medicine. This is worse than brain drain and it may be appropriately called as 'brain decay'. The reasons for not practicing range from loss of interest in the field to more important priorities including family commitments. The study cohort comprised of female doctors in the age group of 26-32 years, at the peak of marital and reproductive period.

Given the distinctly different social role of females, compared to males, it should not be a surprise if some female doctors prioritize family during these years. It was, however, disappointing that more than $50 \%$ of the non-practicing female doctors were not at all interested in continuing with the medical field. The majority of these were well settled abroad after marriage and were not included in the estimation of brain drain (the terminology referring to an actively contributing brain in medicine). The issue of non practicing doctors / changeover of subspecialties has been addressed in research worldwide with non satisfaction with current vocation being the most frequently cited reason. ${ }^{24-27}$
Poor inclination of doctors towards general practice None of the graduates in the study cohort have set up their general practice clinic to. It is also noteworthy that almost $60 \%$ of medical graduates preferred postgraduate medical qualifications rather than proceeding with postMBBS general practice. Concerns have been expressed in the research worldwide over increasing preference of young medical graduates towards specializations and variables influencing the same., ${ }^{9,28-30}$ The importance of primary care doctors in the healthcare delivery system of a country cannot be underestimated. They form the base of any healthcare delivery system pyramid of a country and the one with a narrow base is likely to be unstable. ${ }^{1}$ Apart from being easily available, acceptable and affordable to most people, primary care doctors also reduce the case burden on tertiary health institutions. This ensures better quality of care and appropriate utilization of resources at the tertiary centers. Coupled with good referral system general practitioners could really provide effective primary health care as it was anticipated in the goal of 'Health For All' by the World Health Organization. ${ }^{1}$

\section{Conclusion}

The study concludes that approximately one quarter of the medical graduates, especially females, are no more affiliated to medical profession. Brain drain accounts for the loss of almost $40 \%$ of active medical manpower, thus leaving less than half of the medical graduates to serve the local population. Increased preference for subspecialization and low interest in primary health care oriented general practice is another critical issue.

Allocation of resources to build infrastructures in primary health care will not only increase the human capital absorbing power of the system but also favor the preference of young medical graduates towards primary health care. Health policy should focus on retaining the medical workforce already produced rather than producing the surplus doctors as the real problem is misdistribution and not the shortage. In view of the increasing number of female medical graduates in the recent years coupled with the evidence that majority of these do not practice medicine, it would be prudent to consider attitudinal criteria in eligibility for medical courses in addition to the merit. Statutory measures indicating minimum number of years of practice, or compensation for wasted resources and lost opportunity for a potential medical practitioner could be considered. Adapting the workplace to the needs of women by exempting them from night duties on case to case basis, providing crèche services at the workplace would be encouraging to those 
who wish to practice. Since the data was collected by mailed questionnaire there was little scope to elicit the perceptions and attitudes of these female doctors towards the medical vocation. A well planned qualitative research focused on this sub-set of the study sample could overcome this limitation of the study.

\section{References}

1. Sathe PV, Sathe AP. Epidemiology and Management for Health Care. $2^{\text {nd }}$ ed. (revised). Mumbai: Popular Prakashan, 2003.

2. Mathur SC, Dua AS. NCMH background papers: Financing and delivery of health care services in India. New Delhi: Ministry of Health \& Family Welfare, 2005.

3. Harris JE. How many doctors are enough? Health Affairs 1986;5:73-83.

4. Kaushik M, Roy A, Bang A, Mahal A. Quality of medical training and emigration of physicians from India. BMC Health Serv Res 2008;8:279.

5. Kaushik M, Jaiswal A, Shah N, Mahal A. High -end physician migration from India. Bull World Health Organ 2008;86:40-5.

6. Ahmad OB. Managing medical migration from poor countries $B M J 2005$; 331:43-5.

7. Adkoli BV. Migration of Health Workers: Perspectives from Bangladesh, India, Nepal, Pakistan and Sri Lanka. Regional Health Forum 2006;10:50-8.

8. Medical Council of India. Annual Report 2011 -2012 . Available from http:// w w w. m c i ind i a . org/ A b o u t M C I / AnnualReports.aspx (accessed June 2013)

9. Mullan F. Doctors for the world: Indian physician emigration. Health Aff 2006;25: 380-93.

10. Health Information Bureau. Health StatisticsGoa 2010. Goa: Directorate of Health Services, 2011.

11. Mullan F. The metrics of the physician brain drain. NEJM 2005;353:1810-8.

12. Oommen TK. India: Brain drain or the migration of talent? Int Migr 1989;27:411-25.

13. Premi MK, Mathur MD. Emigration dynamics: the Indian context. Int Migr 1995;33:627-66.

14. Chanda R. Trade in health services. Bull World Health Organ 2002;80:158-63.

15. Bach S. Migration patterns of physicians and nurses: still the same story? Bull World Health Organ 2004;82:624-5.
16. Mejia A. Migration of physicians and nurses: a worldwide picture. Bull World Health Organ 2004;82:626-30

17. Imran N, Azeem Z, Haider II, Amjad N, Bhatti MR. Post Graduation Migration Intentions and the influencing factors among Medical Graduates from Lahore, Pakistan. BMC Res Notes 2011; 17:417.

18. Adams O, Stilwell B. Health Professionals and migration. Bull World Health Organ 2004;82:560

19. Saravia N, Miranda J. Plumbing the brain drain Bull World Health Organ 2004;82 :608-13.

20. Kupfer L, Hofman K, Jarawan R, Mc Dermott J, Bridbord K. Strategies to discourage Brain drain. Bull World Health Organ 2004;82:616-9.

21. Peñaloza B, Pantoja T, Bastías G, Herrera C, Rada G. Interventions to reduce emigration of health care professionals from low- and middleincome countries. Cochrane Database Syst Rev 2011;7:9

22. Stilwell B, Diallo K, Zurn P, Vujicic M, Adams $\mathrm{O}$, Dal Poz M. Migration of healthcare workers from developing countries: strategic approaches to its management. Bull World Health Organ 2004;82:595-600.

23. Ahmad OB. Managing medical migration from poor countries. BMJ 2005; 331:43-5.

24. Donowitz M, Germino G, Cominelli F, Anderson JM. The attrition of young physician-scientists: problems and potential solutions. Gastroenterology 2007;132:477-80.

25. Rittenhouse DR, Mertz E, Keane D, Grumbach K. No exit: an evaluation of measures of physician attrition. Health Serv Res 2004;39:1571-88.

26. Hyppola H, Kumpusalo E, Neittaanmaeki L, Mattila K, Virjo I, Kujala S, Luhtala R. Becoming a doctor: was it the wrong career choice? Soc Sci Med 1998;47:1383-7.

27. Mirtz TA, Hebert JJ, Wyatt LH. Attitudes of non -practicing chiropractors: a pilot survey concerning factors related to attrition. Chiropractic Osteopathy 2010;18:29.

28. Bylsma WH, Arnold GK, Fortna GS, Lipner RS Where have all the general internists gone? $J$ Gen Intern Med. 2010;25:1020-3.

29. Scott I, Gowans M, Wright B, Brenneis F, Banner S, Boone J. Determinants of choosing a career in family medicine. CMAJ 2011;183:E1-E8.

30. Rabinowitz HK, Diamond JJ, Markham FW, Rabinowitz C. Long-term retention of graduates from a program to increase the supply of rural family physicians. Acad Med 2005;80:728-32. 